\title{
Apoptosis during the seasonal spermatogenic cycle of Rana catesbeiana
}

\author{
Estela Sasso-Cerri, ${ }^{1}$ Paulo Sérgio Cerri, ${ }^{1}$ Edna Freymüller ${ }^{2}$ and Sandra Maria Miraglia ${ }^{3}$ \\ ${ }^{1}$ Department of Morphology, Dental School, São Paulo State University (UNESP), Araraquara, Brazil \\ ${ }^{2}$ Electron Microscopy Centre and ${ }^{3}$ Department of Morphology, Federal University of São Paulo (UNIFESP), Brazil
}

\begin{abstract}
In the bullfrog Rana catesbeiana, testicular weight is constant throughout the year, but the volume densities of germinative and interstitial compartments undergo inverse changes from winter (non-breeding) to summer (breeding). The occurrence of apoptosis in the seminiferous lobules of bullfrogs was investigated in these two periods using sections stained with haematoxylin and eosin (H\&E), the TUNEL (terminal deoxynucleotidyl transferase-mediated dUTP nick end labelling) method and transmission electron microscopy. TUNEL-positive cells were observed in the seminiferous lobules, and ultrastructural morphological details confirmed the occurrence of cell death by apoptosis. In summer, the occurrence of several spermatogenic processes (in addition to spermiogenesis and spermiation), and then the overconsumption of Sertoli cell-derived pro-survival factors, could be responsible for the increased density of apoptotic cells. Alternatively, the low apoptotic frequency in winter could be related to the constant homeostasis in the germinative compartment given that most lobules are filled with primary spermatocytes. As volume densities of interstitial and germinative compartments undergo inverse seasonal variations through the year, the incidence of apoptosis (in summer) could play a part in controlling the spermatogenic process, maintaining the lobular size when interstitial tissue is maximally developed. In winter, the low apoptotic cell density leads to spermatogenic recrudescence and, thereby, the production of an adequate quantity of spermatozoa for the next breeding period. Thus, apoptosis may participate not only in the maintenance of spermatogenic homeostasis, but also in the cyclical control of the different spermatogenic processes according to seasonal changes of the testicular compartments as a whole.
\end{abstract}

Key words amphibia; anurans; apoptosis; cell death; germ cells; testis; TUNEL method.

\section{Introduction}

Apoptosis is a physiological process of cell death that occurs during proliferation and differentiation of tissues (Raff, 1998; Cohen, 1999; Lockshin \& Zakeri, 2004). In the testis, apoptosis appears to limit the germ cell population and inhibit maturation of aberrant germ cells (Yin et al. 1998). The absence of essential factors for spermatogenic cycle progression, such as hormones, growth factors or cytokines, leads to apoptosis

\footnotetext{
Correspondence

Dr Estela Sasso-Cerri, Department of Morphology, Dental School, São Paulo State University (UNESP), Rua Humaitá, 1680. CEP -14801-903, Araraquara (SP), Brazil. T: +55 113301 6491; E: esasso@foar.unesp.br Accepted for publication 14 February 2006
}

of their target cells (Tapainainen et al. 1993; BlancoRodríguez, 1998). Moreover, overproliferation of germ cells is avoided by a rapid elimination of surplus germ cells by apoptosis to adjust numbers to the supportive capacity of Sertoli cells (Blanco-Rodríguez, 1998; Lee et al. 1999). Thus, apoptosis is related to the equilibrium between the number of germ cells and the supporting capacity of Sertoli cells, maintaining testicular homeostasis (Lee et al. 1999).

In seasonal breeder vertebrates, spermatogenesis and steroidogenesis undergo transitions from recrudescence to quiescence according to environmental factors that characterize breeding and non-breeding periods (Lofts, 1974; Blottner et al. 1995; Young \& Nelson, 2001; Sasso-Cerri et al. 2004). During breeding periods, the stimulatory environmental factors induce 
secretion of gonadotropins (Young \& Nelson, 2001). By contrast, non-stimulatory environmental factors decrease gonadotropin secretion and reduce steroidogenesis and spermatogenesis during non-breeding periods (Sinha Hikim \& Swerdloff, 1999). The transition from the breeding to the non-breeding state leads to significant testicular atrophy, which has been associated with increased incidence of cell death by apoptosis (Furuta et al. 1994; Blottner et al. 1996; Young \& Nelson, 2001; Strbenc et al. 2003). Taking into account the fact that interrupted proliferation and stimulated apoptosis promote testis involution, it has been suggested that cell proliferation and apoptosis perform an inverse role during the annual cycle in mammalian seasonal breeders (Blottner et al. 1996).

In poikilothermic vertebrates (urodeles) living in temperate zones, spermatogenesis is halted during winter because secondary spermatogonia die by apoptosis (Yazawa et al. 1999). By contrast, species of amphibians living in tropical zones, such as Rana catesbeiana, present a continuous testicular cycle in which the production of spermatogonia and spermatocytes are constant and spermatozoa are found in the seminiferous lobules throughout the year (van Oordt, 1960; Lofts, 1974; Sasso-Cerri et al. 2004). The seasonal spermatogenic cycle of $R$. catesbeiana has been characterized into three distinct phases: (1) a slow initial spermatogenic phase in which the lobules reach maximal diameters and are filled with cysts of primary spermatocytes, in autumn/winter (non-breeding period); (2) an active phase, characterized by meiosis completion, spermiogenesis and early spermiation in spring (breeding period); and (3) a phase in the final breeding period (summer), in which the lobules show minimal diameters and active spermiogenesis/spermiation together with early spermatogenesis (mitosis/meiosis) in the post-spermiation lobules. The interstitial tissue also undergoes seasonal morphometric changes. Thus, in winter the interstitial tissue is scarce when the lobules are maximally developed, whereas in spring and especially in summer, the volume density of the interstitial tissue increases significantly (Sasso-Cerri et al. 2004) and the interstitial cells are strongly testosteroneimmunopositive (Sasso-Cerri et al. 2005). Therefore, considering that the gonadosomatic index (testicular weight per $100 \mathrm{~g}$ body weight) remains constant during the reproductive cycle of $R$. catesbeiana (Licht et al. 1983; Sasso-Cerri et al. 2004), it has been suggested that the compensatory effect of the interstitial tissue when the seminiferous lobules are in regression could explain the maintenance of testicular weight through the year (Sasso-Cerri et al. 2004).

Various studies have demonstrated the role of temperature and endocrine factors on germ cell apoptosis in fish (Prisco et al. 2003) and urodeles (Yazawa et al. 1999, 2000, 2003; Ricote et al. 2002). However, the role of apoptosis on the seasonal spermatogenesis of anurans has not been sufficiently emphasized. Because in $R$. catesbeiana the seminiferous lobules undergo significant morphofunctional variations from winter (non-breeding) to summer (breeding), the frequency of apoptotic cells (TUNEL-positive cells) in the germinative compartment was investigated in these two periods.

\section{Materials and methods}

\section{Animals}

Sixteen adult male bullfrogs (Rana catesbeiana) from the Aquaculture Centre of the Veterinary School of Jaboticabal (São Paulo State University, Brazil) were fed housefly larvae combined with a commercial diet (Nutrimex, Mexico) twice a day. The animals investigated during July $\left(20^{\circ} \mathrm{C}\right)$ and February $\left(36^{\circ} \mathrm{C}\right)$ were divided into winter and summer groups, respectively, containing eight animals each. The study was conducted in accordance with the NIH Guide for the Care and Use of Laboratory Animals (NIH publication 85-23, 1985). The protocol of this study was approved by the Ethical Committee for Animal Research of the Federal University of São Paulo, Brazil.

\section{Tissue preparation for light microscopy}

Five frogs from each group were anaesthetized via an intraperitoneal injection of thiopental and perfusionfixed with Bouin's liquid (Sasso-Cerri et al. 2005). The testes were removed, sectioned, fixed in the same fixative for $15 \mathrm{~h}$, dehydrated and embedded in paraffin for detection of apoptosis by the TUNEL method (terminal deoxynucleotidyl transferase-mediated dUTP nick end labelling) and quantitative analysis (density of apoptotic cells). The remaining three animals from each group were anaesthetized and their right testes were removed, cross-sectioned and fixed by immersion in $4 \%$ formaldehyde (prepared from paraformaldehyde) buffered with $0.1 \mathrm{~m}$ sodium phosphate at $\mathrm{pH}$ 7.2. After $48 \mathrm{~h}$, the testes were dehydrated through a graded 
ethanol series and embedded in glycol methacrylate according to the historesin embedding kit (Jung, Germany). Sections ( $3 \mu \mathrm{m}$ thick) were stained with Gill's haematoxylin and eosin (H\&E) according to Cerri \& Sasso-Cerri (2003) for morphological analysis.

\section{Transmission electron microscopy}

The same animals used for light microscopy (historesin) were perfusion-fixed (Sasso-Cerri et al. 2005) with 3\% glutaraldehyde and $2.5 \%$ formaldehyde (from paraformaldehyde) buffered with $0.1 \mathrm{~m}$ sodium cacodylate at $\mathrm{pH}$ 7.4. The left testes were removed, sectioned into small fragments and maintained in the same fixative for $6 \mathrm{~h}$. The fragments were then washed in sodium cacodylate buffer at $\mathrm{pH} 7.4$ and post-fixed in osmiumreduced ferrocyanide $(0.1 \%$ osmium tetroxide and $1.25 \%$ potassium ferrocyanide) for $1 \mathrm{~h}$ at room temperature. Subsequently, the fragments were treated with an aqueous solution of $1 \%$ uranyl acetate for $2 \mathrm{~h}$. After dehydration through a graded ethanol series, the fragments were treated with propylene oxide and embedded in Araldite.

Toluidine-blue-stained semithin sections were examined in a light microscope for selection of the regions to be trimmed. Ultrathin sections were collected onto grids and stained with uranyl acetate and lead citrate prior to examination in a Jeol 1200 EXII transmission electron microscope $(80 \mathrm{kV})$.

\section{TUNEL method}

Paraffin sections $(6 \mu \mathrm{m})$ were adhered to silanized slides and submitted to the TUNEL method according to the Apop-Tag Plus Peroxidase Kit (Oncor, Inc., Gaithersburg, MD, USA) as previously described (Sasso-Cerri $\&$ Miraglia, 2002). The sections were pretreated with $20 \mu \mathrm{g} \mathrm{mL}^{-1}$ proteinase $\mathrm{K}$ for $10 \mathrm{~min}$ and $3 \%$ hydrogen peroxide for inactivation of endogenous peroxidase. Subsequently, they were incubated in equilibration buffer for $15 \mathrm{~min}$ at room temperature and in a solution containing terminal deoxynucleotidyl transferase (TdT) enzyme at $37^{\circ} \mathrm{C}$ in a humidified chamber for $1 \mathrm{~h}$. The reaction was stopped by immersion in a stop wash buffer at $37^{\circ} \mathrm{C}$ for $20 \mathrm{~min}$. After several washings in PBS (sodium phosphate buffer, $50 \mathrm{~mm}$, containing $200 \mathrm{~mm} \mathrm{NaCl}, \mathrm{pH}$ 7.4), the sections were incubated in anti-digoxigenin antibody conjugated to peroxidase at room temperature for $30 \mathrm{~min}$. The reaction was revealed by DAB (3.3'-diaminobenzidine tetrahydrochloride) and hydrogen peroxide. Nuclear staining was performed by using Mayer's haematoxylin. For negative control of the TUNEL method, some sections were similarly processed, except that the TdT enzyme was substituted by distilled water. Involuting mammary gland sections, provided with the Apop-Tag Kit, were used as positive controls.

The testicular sections stained with H\&E and labelled by TUNEL were examined and photographed under an Olympus BX-50 microscope.

\section{Density of apoptotic cells}

The number of TUNEL-positive germ cells per $\mathrm{mm}^{2}$ seminiferous lobules (apoptotic cell density) was obtained by using an image analysis system (Quantimet 500IW, Leica) attached to a light microscope (Optiphot II, Nikon). Four testicular sections per animal were analysed; from each testicular section, 22 standardised fields/areas were selected, totalling $3960000 \mu \mathrm{m}^{2}$ of testicular tissue per animal. In each field, the area occupied by the seminiferous lobules was computed and the total number of TUNEL-positive germ cells was scored, at $\times 860$ magnification. Thus, the density of apoptotic cells (TUNEL-positive germ cells per $\mathrm{mm}^{2}$ seminiferous lobules) was calculated.

\section{Statistical analysis}

Data were statistically analysed using the software Jandel SigmaStat 2.0. A one-way ANova followed by the Mann-Whitney test was used to compare differences between groups. Significance was accepted at a confidence level of $P \leq 0.05$.

\section{Results}

\section{H\&E and TUNEL method}

In the testicular sections of frogs collected during winter, most of the seminiferous lobules showed numerous cysts of primary spermatocytes. However, spermatogonia, round and elongated spermatids were also observed. A thin layer of interstitial cells was observed around the seminiferous lobules (Fig. 1A). In summer, the seminiferous lobules showed cysts containing different cells of the germinal lineage. Several lobules in spermiation were releasing late spermatids 

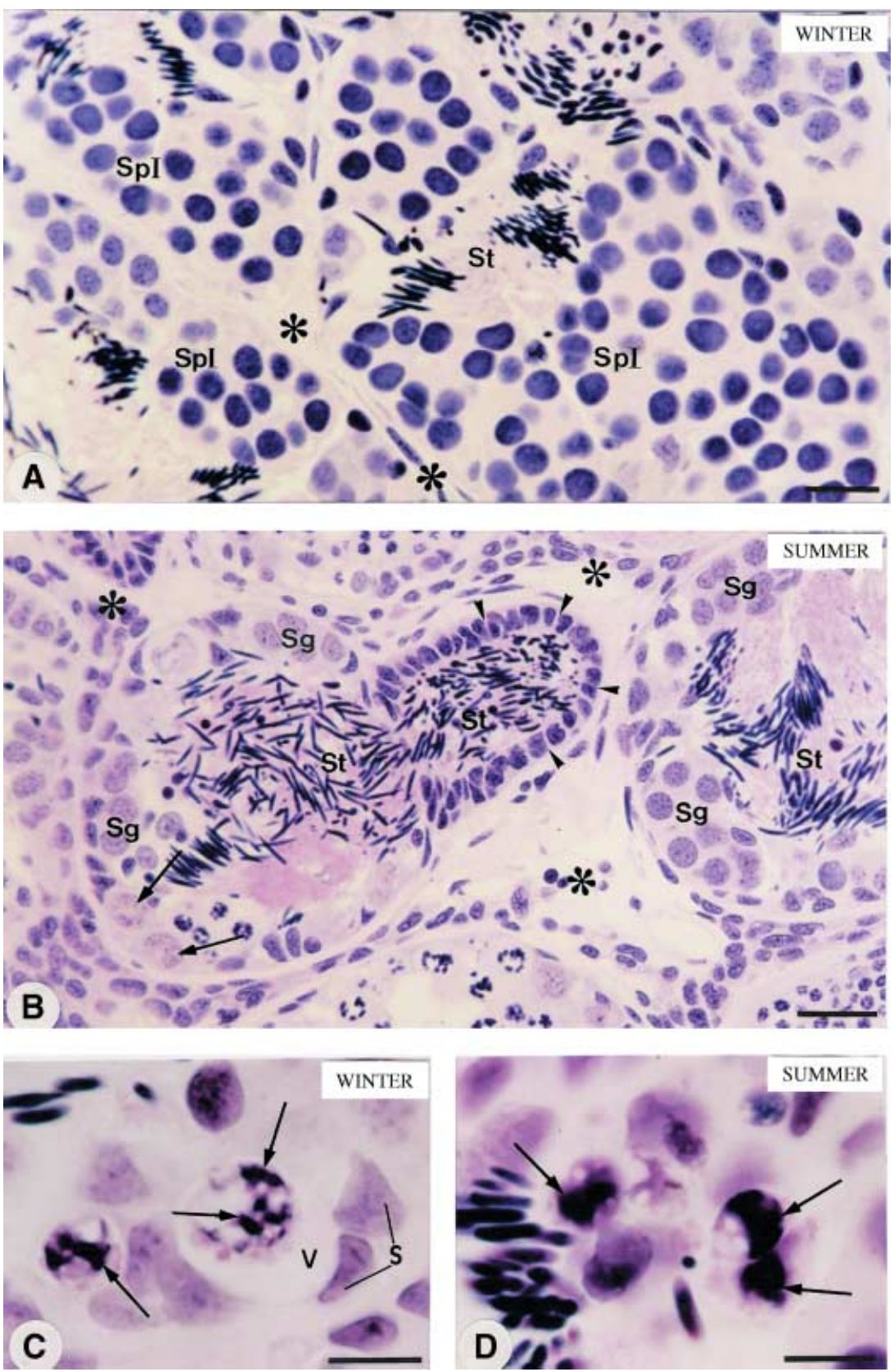

Fig. 1 Photomicrographs of testicular sections of frogs collected during winter $(A, C)$ and summer $(B, D)$. (A) Seminiferous lobules filled with cysts of primary spermatocytes (Spl) and late spermatids (St) are surrounded by a sparse interstitial tissue (asterisks).

(B) Seminiferous lobules, containing some spermatogonia (Sg), primordial germ cells (arrows) and late spermatids (St), are surrounded by a developed interstitial tissue (asterisks).

A seminiferous lobule releases late spermatids (St) into the excretory duct (arrowheads). (C,D) Germ cells nuclei exhibit irregular blocks of condensed chromatin (arrows). In C, one of the germ cells appears to be inside a vacuole (v) surrounded by Sertoli cells (S). H\&E. Scale bars: A, $20 \mu \mathrm{m} ; \mathrm{B}, 30 \mu \mathrm{m}$; C and D, $10 \mu \mathrm{m}$. into the excretory ducts. These lobules showed cysts of spermatogonia and some primordial germ cells (Fig. 1B). In winter, cell nuclei showing clumps of condensed chromatin were occasionally found. By contrast, these cells were frequently observed in the summer group frogs (Fig. 1C,D); sometimes their nuclei seemed to be within vacuoles in close contact with Sertoli cells (Fig. 1C).

The testicular sections subjected to the TUNEL method showed cells stained golden brown, i.e. TUNEL-positive cells, in the seminiferous lobules of frogs from both groups (Fig. 2A,B). In the summer group, a high frequency of TUNEL-positive cells was observed and, in some lobules, several of them were found in the same germ cyst (Fig. 2B). In both groups, stained cells were found next to Sertoli cell nuclei (Fig. 2C,D). Accurately identifying most stained cells was difficult owing to their decreased nuclear volume, damaged nuclear morphology and inexact location in relation to the TUNEL-negative germ cysts (Fig. 2A-D).

The mammary gland sections used for positive controls in the TUNEL method showed numerous cells stained golden brown; the frog testicular sections incubated in the absence of TdT enzyme were negative (data not shown). 
Fig. 2 Photomicrographs of testicular sections of frogs collected in winter (A) and summer (B-D). The TUNEL-positive structures are coloured golden brown. (A) Some TUNEL-positive cells (arrows) are observed in the seminiferous lobules. (B) Numerous TUNEL-positive cells (arrows) are observed in the germ cysts. In C (high magnification of B) and $D$, TUNEL-positive cells (thin arrows) are in close contact with Sertoli cell nuclei (large arrows). Scale bars: A and B, $20 \mu \mathrm{m} ; \mathrm{C}$ and D, $10 \mu \mathrm{m}$.
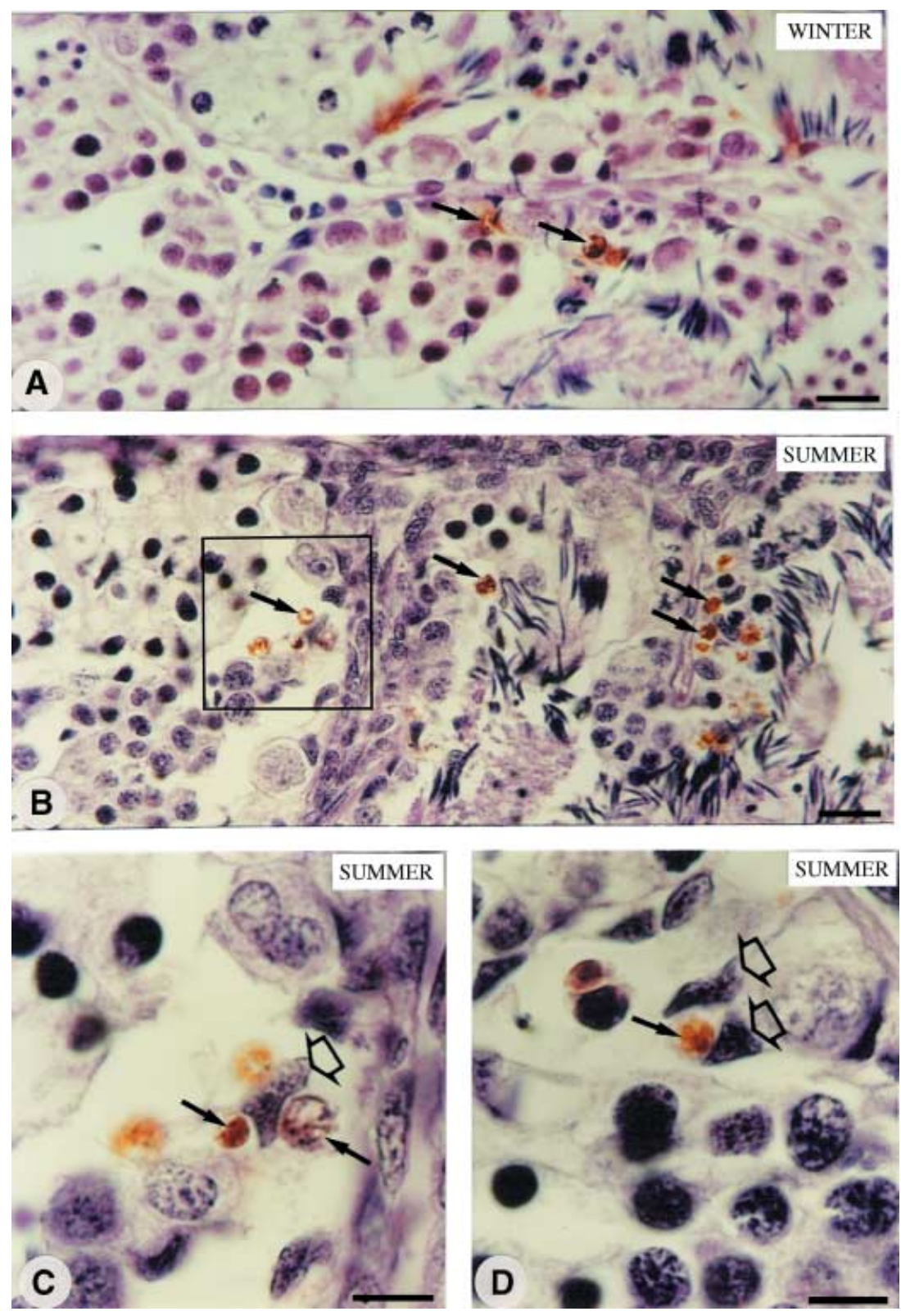

\section{Transmission electron microscopy}

In the germ cysts of frogs from both groups, occasional germ cells showed abnormal ultrastructural aspects (Fig. 3A-C). The germ cells with peripheral electrondense chromatin showed a ring-shaped nucleus (Fig. 3A); in others, the condensed chromatin was sparsely distributed in the nuclear periphery (Fig. 3B). Some nuclei, with clumps of condensed chromatin and granular material, had a complex and heterogeneous appearance; these nuclei seemed to be fragmented. Frequently, portions of electron-dense material similar to chromatin were observed in the germ cell cyto- plasm (Fig. 3B,C). In general, these altered germ cells were in close proximity to the Sertoli cell nucleus, and appeared to be inside the Sertoli cell cytoplasm (Fig. 3B,C). Membranous structures containing chromatin-like material - typical of apoptotic bodies were surrounded by cytoplasmic processes of Sertoli cells (Fig. 3D).

\section{Density of apoptotic cells}

All animals in the summer group showed a statistically significant $(P \leq 0.001)$ increase in the number of TUNELpositive cells per $\mathrm{mm}^{2}$ seminiferous lobules, in comparison 

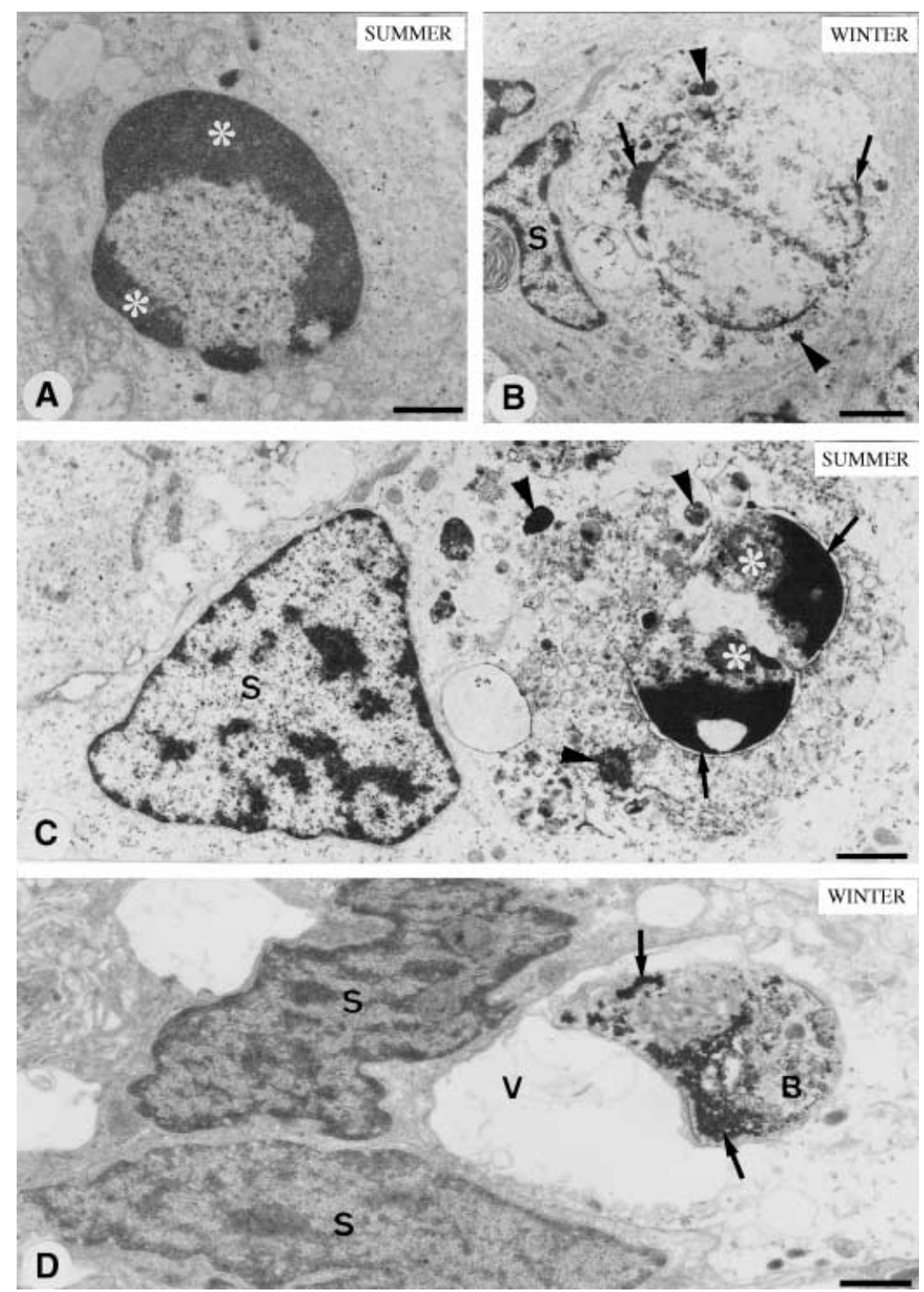

Fig. 3 Electron micrographs of portions of seminiferous lobules of frogs collected during summer $(A, C)$ and winter $(B, D)$. (A) The germ cell exhibits ring-shaped nucleus with peripheral electron-dense chromatin (asterisks).

(B) The Sertoli cell (S) is surrounding a germ cell with fragmented and irregularly distributed chromatin (arrows). Electron-dense material similar to chromatin is observed in the cytoplasm (arrowheads). (C) A germ cell next to the Sertoli cell nucleus (S) shows homogeneous clumps of strongly condensed chromatin (arrows); heterogeneous granular material (asterisks) is also seen. Small structures with variable electron density similar to chromatin (arrowheads) are observed in the cytoplasm. (D) An apoptotic body (B) showing granular electron-dense material similar to nuclear chromatin (arrows) is within a large vacuole (V) delimited by two Sertoli cells (S). Scale bars: $A$ and $D, 1 \mu \mathrm{m} ; \mathrm{B}, 2 \mu \mathrm{m} ; \mathrm{C}, 1.5 \mu \mathrm{m}$. with the animals in the winter group (Table 1). Whereas in winter the density of TUNEL-positive cells was about 28 cells $\mathrm{mm}^{-2}$, in summer this was about 110 cells $\mathrm{mm}^{-2}$. A large variation in apoptotic cell density ( \pm 33.9 cells $\mathrm{mm}^{-2}$ ) was observed among the animals of the summer group compared with the winter group ( \pm 4.7 cells $\mathrm{mm}^{-2}$ ).

\section{Discussion}

Our results showed that the germ cells of $R$. catesbeiana undergo cell death by apoptosis during the seasonal spermatogenic cycle. Cell death by apoptosis includes the participation of proteases (caspases) that induce fragmentation of DNA strands and exposure of terminal $3^{\prime}-\mathrm{OH}$. Among the nuclear morphological changes, chromatin condensation and nuclear fragmentation have been described in different cellular types during apoptosis (Wyllie et al. 1980; Raff, 1998; Lockshin \& Zakeri, 2004). In the present study, the germ cell nuclei of bullfrogs showed typical morphological and ultrastructural aspects of apoptosis (Wyllie et al. 1980; Lockshin \& Zakeri, 2004). Moreover, the TUNEL method revealed positivity in the germ cysts of frogs from both groups. This method for 'in situ' detection of DNA breaks (Gavrieli et al. 1992) has been widely used for detection of cell death in mammal testes (França et al. 2000; Morales et al. 2002; Sasso-Cerri \& Miraglia, 
Table 1 Density of apoptotic cells (TUNEL-positive cells per $\mathrm{mm}^{2}$ seminiferous lobules) in the winter- and summer-group frogs

\begin{tabular}{llc}
\hline Animals & Winter & Summer* \\
\hline 1 & 31 & 99 \\
2 & 23 & 75 \\
3 & 28 & 137 \\
4 & 35 & 80 \\
5 & 25 & 160 \\
& $28 \pm 4.77$ & $110 \pm 33.99$ \\
\hline
\end{tabular}

$* P \leq 0.001$

2002; Stumpp et al. 2004) and in tissues of anurans (Barni et al. 2002; Accordi \& Chimenti, 2003). In contrast to necrosis, apoptosis is a physiological process in which the apoptotic bodies are immediately recognized by neighbouring cells and phagocytosed, avoiding the inflammatory process (Raff, 1998; Lockshin \& Zakeri, 2004). During spermatogenesis, germ cells undergo apoptosis and are phagocytosed by Sertoli cells (Allan et al. 1992; Shiratsuchi et al. 1997; Sasso-Cerri \& Miraglia, 2002). Under light microscopy, our results showed some germ cell nuclei surrounded by a vacuolelike halo and were in close contact with Sertoli cell nuclei. Moreover, some germ cells showing ultrastructural characteristics that are typical of apoptosis, and membranous structures - probably apoptotic bodies - appeared to be within the Sertoli cell cytoplasm. Thus, we concluded that testicular germ cells of $R$. catesbeiana undergo apoptosis and are phagocytosed by neighbouring Sertoli cells.

The role of temperature (Yazawa et al. 1999, 2003; Ricote et al. 2002) and photoperiod (Furuta et al. 1994; Blottner et al. 1995, 1999; Young et al. 1999, 2001) in the control of apoptosis during seasonal spermatogenesis of vertebrates has been discussed. In the present study, an increased incidence of apoptosis was observed in the testes of frogs collected in summer, a final breeding period characterized by long photoperiods and high temperature. In the testes of avian seasonal breeders, apoptosis increases significantly after chronic photostimulation (Young et al. 2001). It is possible that the prolonged photoperiod in summer, by means of activation of endocrine factors, is responsible for the increase in cell death. Some authors have suggested that temperature has no influence on apoptosis in urodeles (newts), as increased incidence of cell death was observed both in winter and in summer (Ricote et al. 2002). However, in newts, winter corresponds to a quiescent period (low germ cell proliferation and absence of meiosis), probably owing to the lower temperatures than in tropical zones. In these species, low temperature induces secondary spermatogonia cell death and spermatocytes are not found in winter (Yazawa et al. 1999). It has been suggested that the arrest in spermatogenesis in winter seems to prevent the production of abnormal spermatozoa, being favourable to the survival of these species (Yazawa et al. 2003). In R. catesbeiana (living in tropical zones), the winter period is characterized by the production of numerous primary spermatocytes to guarantee a satisfactory number of spermatozoa for the next breeding season (spring). Thus, the difference in the incidence of apoptosis between these two species in winter may be due to the different temperatures of the geographical zones in which these species live.

Blottner et al. (1999) suggested that the regulation of seasonal testicular activity is characterized by coordinated shifts in the relationship between mitosis, meiosis, apoptosis and testosterone production. In the present study, a low incidence of apoptosis in winter is related to spermatogenic recrudescence and maximal development of the seminiferous lobules. Otherwise, the activation of apoptosis occurs in summer, a final spermatogenic phase, in which spermiogenesis and spermiation take place and most lobules reach minimal diameters (Sasso-Cerri et al. 2004). These results are in agreement with the inverse correlation between apoptosis and germ cell proliferation verified in seasonal breeders (Blottner et al. 1996; Young \& Nelson, 2001; Strbenc et al. 2003). Although spermiogenesis and spermiation take place in summer, other cellular processes (i.e. mitosis and meiosis) also occur during this period and a new spermatogenic cycle begins in the post-spermiation lobules (Sasso-Cerri et al. 2004). In newts, Ricote et al. (2002) have suggested that the occurrence of apoptosis in a period not conducive to spermiogenesis could prevent excessive spermatogonial proliferation and meiosis. Moreover, the inability of Sertoli cells to provide all necessary regulatory factors to germ cells could provoke a suboptimal milieu for normal spermatogenesis. Thus, as proposed by Neubauer et al. (2004), apoptosis could act as a form of 'quality control', avoiding some degree of teratozoospermia. It is possible that, in summer, depletion of survival factors and activation of apoptosis can be caused by the concomitant occurrence of different cellular processes (mitosis, meiosis, spermiogenesis and spermiation). This hypothesis 
is supported by the fact that a low apoptotic frequency was observed in winter, when the seminiferous lobules seem to be in a constant homeostasis, given that most of the germ cysts are, synchronously, at the same stage of spermatogenesis (Meiosis I). Moreover, the variation in apoptotic cell density among the animals of the winter group was minimal $\left( \pm 4.7\right.$ cells $\mathrm{mm}^{-2}$ ) compared with that of the summer group ( \pm 33.9 cells $\mathrm{mm}^{-2}$ ).

The low incidence of apoptosis in winter is favourable to the fast spermatogenic recrudescence and increase in the diameter of the seminiferous lobules from late summer to autumn/winter (Sasso-Cerri et al. 2004). In this way, numerous primary spermatocytes are produced, to guarantee an adequate number of spermatozoa for the next breeding period (spring). Otherwise, it is not clear what mechanism is responsible for the control of the maximal cellular density to be supported within the lobules in winter. Given that, in winter, the cytoplasm of primordial germ cells (stem cells) shows an immunopositive testosterone concentration, a possible role of testosterone on the mitotic activity of primordial germ cells may be related to the control of cellular density in the maximally developed lobules (Sasso-Cerri et al. 2005).

In most seminiferous lobules (75\%) of R. catesbeiana, diameters decrease from $150-300 \mu \mathrm{m}$ in winter to 100 $200 \mu \mathrm{m}$ in summer. The seminiferous lobules showing minimal diameters exhibit only late spermatids and spermatogonia, and some of them usually release late spermatids (spermiation) into the excretory ducts (Sasso-Cerri et al. 2004), as confirmed in the present study. In $R$. esculenta, after a winter stasis, only spermatogonia and spermatozoa were observed in the germinal compartment, owing to the degeneration of the other germinal stages (for a review see Pierantoni et al. 2002). In hamsters (rodent seasonal breeders), the incidence of apoptosis has been related to regression of seminiferous epithelium (Morales et al. 2002), a decrease in tubular diameters and the overwhelming presence of spermatogonia and some primary spermatocytes (Bergmann, 1987). Thus, in addition to spermiogenesis and spermiation, the significant reduction of lobular diameters in frogs in the summer group may also be due to the increase in apoptosis in the germ cysts.

Studies into germ cell death in seasonal breeders have correlated the incidence of apoptosis with testicular regression (Furuta et al. 1994; Blottner et al. 1996; Young \& Nelson, 2001; Strbenc et al. 2003). In species with a continuous testicular cycle such as $R$. catesbeiana, the gonadosomatic index remains constant through the annual reproductive cycle (Licht et al. 1983; Sasso-Cerri et al. 2004). Considering that the volume density of interstitial tissue and excretory ducts increases concomitantly with the decrease in seminiferous lobules, a possible compensatory effect on the volume of these compartments has been related to the maintenance of testicular weight in this species (Sasso-Cerri et al. 2004). The increase in interstitial tissue is due to the differentiation of interstitial cells and intense testosterone production (Sasso-Cerri et al. 2005), which occur concomitantly with or just after the decline in seminiferous lobules (Sasso-Cerri et al. 2004). It has been suggested that alterations of the interstitial tissue-seminiferous lobules contact, due to reduction of the lobules in spermiation, could lead to the development of adjacent interstitial tissue (Sasso-Cerri et al. 2004). Thus, although seminiferous lobules decrease in summer, testicular weight remains constant because interstitial tissue develops and produces testosterone to guarantee spermiogenesis and spermiation as well as the development of secondary sexual characteristics and mating behaviour. In Syrian hamsters, the increase in apoptosis in germ cells may be related to the maintenance of the regression state of the seminiferous epithelium until the beginning of spermatogenic recrudescence (Morales et al. 2002). At least in $R$. catesbeiana, we suggest that the incidence of apoptosis in summer may be favourable for the maintenance of the regressed lobules when the interstitial tissue is significantly increased, avoiding the excessive expansion of the testis.

Therefore, apoptosis not only plays a role in the turnover of the germ cysts, but may also participate in the control of the different phases of the spermatogenic cycle in synchrony with the seasonal changes of the testicular compartments as a whole.

\section{References}

Accordi F, Chimenti C (2003) Retinol-induced apoptosis in larval pancreas of Bufo bufo. J Anat 202, 309-314.

Allan DJ, Harmon BV, Roberts SA (1992) Spermatogonial apoptosis has three morphologically recognizable phases and shows no circadian rhythm during normal spermatogenesis in the rat. Cell Prolif 25, 241-250.

Barni S, Vaccarone R, Bertone V, Fraschini A, Bernini F, Fenoglio C (2002) Mechanisms of changes to the liver pigmentary component during the annual cycle (activity and hibernation) of Rana esculenta L. J Anat 200, 185-194.

Bergmann M (1987) Photoperiod and testicular function in Phodopus sungorus. Adv Anat Embryol Cell Biol 105, 1-76. 
Blanco-Rodríguez J (1998) A matter of death and life: the significance of germ cell death during spermatogenesis. Int $J$ Androl 21, 236-248.

Blottner S, Hingst O, Meyer HHD (1995) Inverse relationship between testicular proliferation and apoptosis in mammalian seasonal breeders. Theriogenology 44, 320-328.

Blottner S, Hingst O, Meyer HHD (1996) Seasonal spermatogenesis and testosterone production in roe deer (Capreolus capreolus). J Reprod Fertil 108, 299-305.

Blottner S, Roelants H, Wagener A, Wenzel UD (1999) Testicular mitosis, meiosis and apoptosis in mink (Mustela vison) during breeding and non-breeding seasons. Anim Reprod Sci 57, 237-249.

Cerri PS, Sasso-Cerri E (2003) Staining methods applied to glycol methacrylate embedded tissue sections. Micron 34, 365-372.

Cohen JJ (1999) Apoptosis: mechanism of life and death in the immune system. J Allergy Clin Immunol 103, 584-554.

França LR, Leal MC, Sasso-Cerri E, Vasconcelos A, Debeljuk L, Russell LD (2000) Cimetidine (Tagamet) is a reproductive toxicant in male rats affecting peritubular cells. Biol Reprod 63, 1403-1412.

Furuta I, Porkka-Heiskanen T, Scarbrough K, Tapanainen J, Turek FW, Hsueh AJW (1994) Photoperiod regulates testis cell apoptosis in Djungarian hamsters. Biol Reprod 51, 13151321.

Gavrieli Y, Sherman Y, Bem-Sasson AS (1992) Identification of programmed cell death in situ via specific labeling of nuclear DNA fragmentation. J Cell Biol 119, 493-501.

Lee J, Richburg JH, Shipp EB, Meistrich ML, Boekelheide K (1999) The Fas system, a regulator of testicular germ cell apoptosis, is differentially up-regulated in Sertoli cell versus germ cell injury of the testis. Endocrinology 140, 852-858.

Licht P, McCreery BR, Barnes R, Pang R (1983) Seasonal and stress related changes in plasma gonadotrophins, sex steroids, and corticosterone in bullfrog, Rana catesbeiana. Gen Comp Endrocrinol 50, 124-145.

Lockshin RA, Zakeri Z (2004) Apoptosis, autophagy, and more. Int J Biochem Cell Biol 36, 2405-2419.

Lofts B (1974) Reproduction. III. The male. In Physiology of the Amphibia, Vol. II (ed. Lofts B), pp. 115-161. New York: Academic Press.

Morales E, Pastor LM, Ferrer C, et al. (2002) Proliferation and apoptosis in the seminiferous epithelium of photoinhibited Syrian hamsters (Mesocricetus auratus). Int J Andro/ 25, 281-287.

Neubauer K, Jewgenow K, Blottner S, Wildt DE, Pukazhenthi BS (2004) Quantity rather than quality in teratospermic males: a histomorphometric and flow cytometric evaluation of spermatogenesis in the domestic cat (Felis catus). Biol Reprod 71, 1517-1524.

van Oordt PGWJ (1960) The influence of the internal and external factors in the regulation of the spermatogenic cycle in amphibia. Zool Soc London Symp 2, 29-52.

Pierantoni R, Cobellis G, Meccariello R, et al. (2002) The amphibian testis as model to study germ cell progression during spermatogenesis. Comp Biochem Physiol Part B 132, 131-139.

Prisco M, Liguoro A, Comitano R, et al. (2003) Apoptosis during spermatogenesis in the spotted ray Torpedo marmorata. Mol Reprod Dev 64, 341-348.
Raff M (1998) Cell suicide for beginners. Nature 396, 119-122.

Ricote M, Alfaro JM, García-Tuñón I, et al. (2002) Control of the annual testicular cycle of the marbled-newt by p53, 21, and Rb gene products. Mol Reprod Dev 63, 202-209.

Sasso-Cerri E, Miraglia SM (2002) In situ demonstration of both TUNEL-labeled germ cell and Sertoli cell in the cimetidine-treated rats. Histol Histopathol 17, 411-417.

Sasso-Cerri E, Faria FP, Freymüller E, Miraglia SM (2004) Testicular morphological changes during the seasonal reproductive cycle in the bullfrog Rana catesbeiana. J Exp Zool 301A, 249-260.

Sasso-Cerri E, Freymüller E, Miraglia SM (2005) Testosteroneimmunopositive primordial germ cells in the testis of the bullfrog, Rana catesbeiana. J Anat 206, 519-523.

Shiratsuchi A, Umeda M, Ohba Y, Nakanishi Y (1997) Recognition of phosphatidylserine on the surface of apoptotic spermatogenic cells and subsequent phagocytosis by Sertoli cells of the rat. J Biol Chem 272, 2354-2358.

Sinha Hikim AP, Swerdloff RS (1999) Hormonal and genetic control of germ cell apoptosis in the testis. Rev Reprod 4, 38-47.

Strbenc M, Fazarinc G, Bavdek SV, Pogacnik A (2003) Apoptosis and proliferation during seasonal testis regression in the brown hare (Lepus europaeus L.). Anat Histol Embryol 32, 48-53.

Stumpp T, Sasso-Cerri E, Freymüller E, Miraglia SM (2004) Apoptosis and testicular alterations in albino rats treated with etoposide during the prepubertal phase. Anat Rec 279A, 611-622.

Tapainainen JS, Tilly JL, Vihko KK, Hsueh AJW (1993) Hormonal control of apoptotic cell death in the testis: gonadotrophins and androgens as testicular cell survival factors. Mol Endocrinol 7, 643-650.

Wyllie AH, Kerr JFR, Currie AR (1980) Cell death: the significance of apoptosis. Int Rev Cytol 68, 251-306.

Yazawa T, Yamamoto K, Kikuyama S, Abé S-I (1999) Elevation of plasm prolactin concentrations by low temperature is the cause of spermatogonial cell death in the newt, Cynops pyrrhogaster. Gen Comp Endocrinol 103, 302-311.

Yazawa T, Yamamoto T, Abé S-I (2000) Prolactin induces apoptosis in the penultimate spermatogonial stage of the testes in japanese red-bellied newt (Cynops pyrrhogaster). Endocrinology 141, 2027-2032.

Yazawa T, Nakayama Y, Fujimoto K, et al. (2003) Abnormal spermatogenesis at low temperatures in the japanese redbellied newt, Cynops pyrrhogaster: possible biological significance of the cessation of spermatocytogenesis. Mol Reprod Dev 66, 60-66.

Yin Y, Stahl BC, DeWolf WC, Morgentaler A (1998) P53mediated germ cell quality control in spermatogenesis. Dev Biol 204, 165-171.

Young KA, Zirkin BR, Nelson RJ (1999) Short photoperiod induces testicular apoptosis in the white-footed mouse (Peromyscus leucopus). Endocrionology 140, 1331-1339.

Young KA, Ball GF, Nelson RJ (2001) Photoperiod-induced testicular apoptosis in European starlings (Sturnus vulgaris). Biol Reprod 64, 706-713.

Young KA, Nelson RJ (2001) Mediation of seasonal testicular regression by apoptosis. Reproduction 122, 677-685. 